\title{
Manning the cannons at ICI
}

London

"I'VE seen no bid. Maybe you know something I don't." This is how Sir Denys Henderson, chairman of Imperial Chemicals Industries (ICI), waves away a reporter's questions about a threatened takeover. Over at Hanson PLC, from where the assault is to supposed to come, the same question draws blank stares. "Bid? I have no idea what you are talking about," a spokesman says, deadpan.

For three months now, Britain's largest research corporation and its most notorious company-acquiring conglomerate have maintained this straight-faced charade. Despite Hanson's menacing purchase of nearly three per cent of ICI in May, the notorious corporate raider has so far made no public move to take the rest of the company, beyond a standing offer of an amicable merger.

Nevertheless researchers, some 13,000 of whom work for ICI or collaborate directly with its scientists, have watched the manoeuvring nervously. A takeover attempt could mean substantial cuts in research, either to raise money to thwart the bid, or, if Hanson is successful, to generate short-term profits for the bottom-line obsessed conglomerate.

Last week, 23 leading academics and members of the Royal Society signed a letter to the London Times airing their fears about a takeover. "Hanson is good at its own business, but it has far less experience in running a researchintensive business like chemicals," they wrote, citing the fact that ICI spends about $£ 679$ million ( 5.3 per cent) of its total sales on research, while Hanson's research and development budget (totalled over the nearly three dozen companies that make up the conglomerate) is only some $£ 34$ million ( 0.4 per cent) of total sales.

\section{Hanson: research versus the bottom-line}

What do Jacuzzis, bricks, fish oil and easy-listening radio have to do with research? Not much, and that is what worries scientists most about Hanson's threatened takeover attempt of $\mathrm{ICl}$.

Essentially, Hanson is a conglomerate with no special industrial focus. It owns more than 30 companies in the United States and Britain, ranging from construction and building industries to manufacturers of consumer products. Besides baths and bricks, its subsidiaries make such products as vitamins and concrete - basic goods that require little new technology.

By design, Hanson has acquired few companies that do research. The 'Hanson formula' is aimed at quick profits and accelerated product development, not
Like its US rival Du Pont, ICI is primarily a chemicals company, although it also has large pharmaceutical and agriculture arms. It is the company that invented polyester, polyethylene and beta blocker heart drugs, as well as being the first to launch both a CFC replacement and a biodegradable plastic. In pharmaceutical, it now concentrates on cancer and cardiovascular fields, and has six anti-cancer drugs in the pipeline.

ICI spends about $£ 7$ million on some 60 collaborations with UK academic scientists, and $£ 2$ million on joint projects outside Britain. Those links, the scientists warned in the letter to the Times, "could be quickly destroyed by short-term savings which significantly reduced research, thinned out technological capabilities and altered scientific collaborations that are essential for the long-term competitiveness of the company."

In fact, the very threat of a bid has already spurred ICI to trim research. Desperate for an encouraging quarter of profits, ICI decided earlier this year to abandon much of the high-performance materials business, where it had been hit by tough competition in the United States from General Electric and a peace-time decline in the aerospace industry, which uses the sort of high-temperature plastics and composites that ICI was developing. It has already begun to shut down most of its advanced materials research operation, a process that will eventually mean a reduction of $£ 30-50$ million in research and development and a loss of some 250-300 research positions.

But the worst may be over. Last week, ICI, which owes its vulnerability to a half-decade of diminishing profits, counterattacked with the first results of its promised $£ 300$ million restructuring: it announced profits that, while still one- third lower than the first half of last year, were well above expectations in the midst of a recession. As the restructuring takes effect, Sir Denys promises even stronger performance in the months to come, something he hopes will restore shareholder confidence in its management and take the wind out of Hanson's sails.

The Hanson threat may actually have galvanized ICI to make some changes to improve the company's position in the years to come. Although cuts and streamlining are still in the cards, research as a whole appears likely to miss the axe. Since 1984, ICI has increased its research spending some 70 per cent relative to total sales, 30 per cent more than the average UK chemical company. Unlike some US companies that responded to takeover threats by selling research arms to generate cash, ICI "has no plans to sell off any R\&D to fight a takeover bid," says research director Peter Doyle.

A study by the Science Policy Research Unit at the University of Sussex shows that ICI's research has steadily improved over most of the past decade, especially in comparison to its UK competition. Worldwide, the picture is not as encouraging, however; although ICI is among the top 20 companies in six US patent areas, it is well behind competitors such as Du Pont (top 20 in 14 areas) and Bayer (top 20 in 10 areas).

The trend, however, is on ICI's side. A study by CHI Research, a US innovation analysis company commissioned by ICI to evaluate its research and development, found that the ICI's technical strength, as measured by both the quantity and the quality of its patents, has increased from 3.77 in 1986 to 6.9 in 1989 . Although that is still behind Dupont (12) and Bayer (9.7), it is well above the industry average of 1.3. And the current restructuring, while cutting costs across the board, is not expected to hit research as hard as other sectors. Christopher Anderson long-term projects. The corporate philosophy consists mostly of selling off or closing the least productive sectors of a newly acquired company and decentralizing management in the remainder to give local managers the responsibility for improving productivity. When Hanson does acquire a coinpany that has a significant research component, its policy is to move research groups closer to production facilities, to ensure that research and development is focused on areas that will quickly turn out marketable products.

Perhaps the best example is British Ever Ready, the UK counterpart of the US battery manufacturer. After acquiring the company (then called Berec) in 1981 , Hanson quickly sold its Abingdon-based
Advanced Projects Group to the researchers themselves. Hanson then moved a smaller Ever Ready research and development team from London to a battery factory in northeastern Britain.

One study estimates that Hanson might cut 15,000 jobs if it took over $\mathrm{ICl}$, part of a fat-trimming exercise aimed at increasing profits at the chemical giant. Research would almost certainly suffer. On the other hand, Hanson has grown over ten-fold in the past decade; last year it had profits of $£ 1,285$ million on $£ 7,153$ million worth of sales. It had to make harsh cuts in the companies it acquired to get there, but many of them subsequently saw profitability for the first time in years. 